\title{
Ligneous Cervicovaginitis Associated with Plasminogen Deficiency: A Rare Cause of Infertility
}

\author{
Aysin AKDOGAN', Gulnaz SAHIN', Levent AKMAN², Deniz SIMSEK², Osman ZEKIOGLU, \\ Ege N.T. GOKER ${ }^{1,2}$, Erol TAVMERGEN ${ }^{1,2}$
}

\footnotetext{
${ }^{1}$ Ege University, Family Planning And Infertility Research and Treatment Center

${ }^{2}$ Ege University Faculty of Medicine, Department of Obstetrics and Gynecology

${ }^{3}$ Ege University Faculty of Medicine, Department of Pathology, Izmir, TURKEY
}

\section{Dear Editor,}

Ligneous inflammation is a rare, chronic disorder that is distinguished by its unique appearance and characterized by ligneous (pseudomembranous) plaques on mucosal surfaces. Ocular mucosa is the most common site of involvement. The upper and lower respiratory tract, ear mucosa and genital system are other sites of frequent involvement. ${ }^{1-3}$ Type 1 plasminogen deficiency which is a form of inherited hypoplasminogenemia is the cause of the disease. It can be detected in the people with homozygous and compound heterozygous mutations in the plasminogen gene. A decrease in the level of plasminogen leads to alteration of the fibrinolytic system and fibrin deposition occurs during wound healing. ${ }^{4}$ In this report, we presented a 27 -year-old infertile woman who had ligneous cervicovaginitis related to type I plasminogen deficiency.

A 27-year-old female patient was admitted to our clinic with the complaint of infertility. The patient also had dysmenorrhea and heavy vaginal discharge. Pelvic examination with speculum revealed whitebeige-colored viscous discharge in the $1 / 3$ upper part of vagina. After cleaning discharge, numerous white plaques were detected on vaginal and cervical mucosa (Figure 1a). Bimanual vaginal examination and ultrasound examination showed no abnormal finding. In the laboratory examination; FSH, LH, Prolactin, thyroid function tests, serological tests, complete blood count and routine biochemical tests were found to be normal. The partner's spermiogram was within normal ranges. Her medical history revealed two cycles of clomiphene citrate and intrauterine insemination. Biopsy was performed from vaginal and cervical plaques. Histopathological examination revealed deposits of eosinophilic, amorphous collagen type 4 and focal staining material under the squamous epithelium, which support diagnosis of chronic phase of ligneous vaginitis. Imunohistochemical analysis staining showed pancytokeratin (+), CD3 (-), CD10 $(-)$, and from hystochemical analysis collagen type 4 focal (+), mason trichome (+), elastic von Gieson (-), PTAH (-), amyloid (-). In the systemic evaluation of the patient, her ocular examination was normal. For dental examination, gingival biopsy specimen was taken because of complaints of chronic periodontitis, and occlusive focal ulceration and nonspecific findings characterized by squamous hyperplasia, subepithelial significant hyalinization were detected (Figure 1b). Plasminogen functional activity was $18 \%$ (reference, 55-145\%). In order for the regression of the lesions we began oral contraceptive therapy to our patient.

Ligneous inflammation is a rare autosomal recessive disorder caused by type 1 plasminogen deficiency which is a form of inherited hypoplasminogenemia, which is known to cause systemic diseases. Female genital tract involvement is determined in $8 \%$ of patients with hereditary hypoplasminogenemia. 


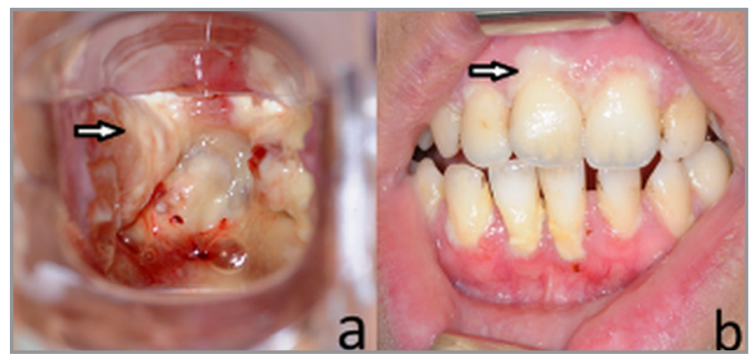

Figure 1a. Ligneous plagues around the cervix b. Focal ulceration around the gingiva.

Patients are usually asymptomatic, while primary infertility, dysmenorrhea, postcoital bleeding and abnormal cytological findings may be the early warning symptoms. Ocular involvement is not detected in half of these patients. In the female genital tract, cervix and vagina are the most frequent sites of involvement.

Also, two cases of tubal, 2 cases of ovarian, and 1 case of endometrial involvement, and 1 case of parametrial involvement in addition to mucosal involvement have been reported in the literature..$^{2-5}$ Patients with genital involvement can be asymptomatic and very rare seen, and hence it is often difficult to diagnose. Definitive diagnosis can be confirmed with histopathological examination of inflamed specimens. In the histopathological examination of the lesions, infiltration of inflammatory cells with large and dense eosinophilic cellular deposits and PAS (periodic acid-Schiff)-positive amorphous material was detected. Amorphous deposits contain fibrillar material with dense fibrin deposits. However, measurement of active and immunoreactive plasminogen is diagnostic.

Inflammation of the cervix, endometrium and fallopian tube may eventually cause infertility as a result of dysfunction. In addition, fibrin plays a role during ovulation and resorption and may causes ovarian disorders, and eventually infertility. ${ }^{6}$ After the diagnosis is confirmed decision of treatment planning is critical. There are no general treatment guidelines. Various local and systemic therapeutic agents have been tested for treatment. The replacement therapy with intravenous lys-plasminogen has been shown to improve ocular and tracheobronchial symptoms of ligneous conjunctivitis significantly. ${ }^{7}$ However, half-life of the protein is short and long time infusion is required. Therefore, this treatment reserved for the most serious systemic cases. Venous thromboembolism was not observed in these patients. ${ }^{8}$ Mostly, local therapies are defined in the literature. Local excision, topical treatments containing heparin and corticosteroids can be used in cases with conjunctiva involvement, also amniotic membrane transplantation, topical and systemic fresh frozen plasma treatments are used. ${ }^{9,10}$ In some studies, topical hydrocortisone application in the vagina has been reported to reduce vaginal discharge and cervical inflammation. ${ }^{11}$ In the literature, oral contraceptives were shown to increase blood levels of plasminogen. ${ }^{12}$ In order for the regression of the lesions we began oral contraceptive therapy to our patient. The treatment was recommended to be continued until the infertility treatment and in the second month of the treatment, reduction of vaginal discharge was observed.

Although ligneous inflammation is a rarely seen disease in clinical practice, it should be considered in primary infertile women with fragile bleeding, discharge, dispareunia, and dysmenorrhea. Systemic features of the disease should be kept in mind. Oral contraceptive drugs caused an increase in plasminogen levels, though new treatment modalities are required due to fertility intention of the patients.

\section{REFERENCES}

1. Aslan AT, Ozcelik U, Dogru D, et al. Congenital hydrocephalus as a rare association with lignous conjuctivitis and type I plasminogen deficiency. Neuropediatrics 36:108-11,2005.

2. Kayikcioglu F, Bulbul D, Celiker S, et al. Ligneous inflammation of the cervix: a case report. J Reprod Med 50: 801804,2005 .

3. Scurry J, Planner R, Fortune DW, et al. Ligneous (pseudomembranous) inflammation of the female genital tract. A report of two cases. J Reprod Med 38: 407-412,1993.

4. Lotan TL, Tefs K, Schuster V. Inherited plasminogen deficiency presenting as ligneous vaginitis: a case report with molecular correlation and review of the literature. Human Pathology 38: 1569-1575, 2007.

5. Altinkaya SO, Uzunlar O, Talas BB, et al. Ligneous cervicovaginitis. Taiwan J Obstet Gynecol 47: 363-366, 2008. 
6. Ny A, Leonardsson G, Hagglund AC et al. Ovulation in plasminogen-deficient mice. Endocrinology 140: 5030-5035,1999.

7. Schott D, Dempfle CE, Beck P, et al. Therapy with a purified plasminogen concentrate in an infant with ligneous conjunctivitis and homozygous plasminogen deficiency. N Engl J Med 339: 1679-86,1998.

8. Ciftci $\mathrm{E}$, Ince $\mathrm{E}$, Akar N, et al. Ligneous conjuctivitis, hydrocephakus, hydrocele, and pulmonary involvement in a child with homozygous type I plasminogen deficiency. Eur J Pediatr 162: 462-465, 2003.

9. Gürlü VP, Demir M, Alimgil ML, et al. Systemic and topical fresh-frozen plasma treatment in a newborn with ligneous conjunctivitis. Cornea 27: 501-503,2008.

10. Klammt J, Kobelt $L$, Aktas $D$, et al. Identification of three novel plasminogen (PLG) gene mutations in a series of 23 patients with low PLG activity. Thromb Haemost 105: 454-460, 2011.

11. Buck DC, Ridley CM. Ligneous conjunctivitis involving the cervix. Case report. Br J Obstet Gynaecol 97: 193,1990.

12. Teresa Sartori M, Saggiorato G, Pellati D, et al. Contraceptive pills induce an improvement in congenital hypoplasminogenemia in two unrelated patients with ligneous conjunctivitis. Thromb Haemost 90: 86-91, 2003.

\section{Correspondence}

Dr. Levent AKMAN

Ege Üniversitesi Tıp Fakültesi

Kadın Hastalıkları ve Doğum Anabilim Dalı

Bornova, IZMIR / TURKEY

Tel: (+90.232) 3901700

e-mail: leventakman@gmail.com 